\title{
Influence of Empty Fruit Bunch Stalk and Spikelet Fibres on the Mechanical Properties of Cement-stabilised Soil
}

\author{
Yakum Reneta $\mathrm{Nafu}^{1,3, *}$, Josepha Foba-Tendo ${ }^{2}$, Ebenezer Njeugna ${ }^{3}$. \\ ${ }^{1}$ Department of Mechanical Engineering, HigherTechnical Teacher Training College, The University of Bamenda \\ Bambili, Cameroon \\ ${ }^{2}$ Department of Chemistry, Faculty of Science \\ University of Buea, Cameroon
}

${ }^{3}$ Department of Mechanical Engineering, Ecole Normal Superieur d'Enseignement Technique (ENSET)

University of Douala, Cameroon

*Corresponding author's email: yakumnafu [AT] gmail.com

\begin{abstract}
The performance of natural-fibre reinforced cement stabilized soil prepared differently with stalk and spikelet from empty fruit bunch (EFB) was investigated. Standard test specimens were prepared with fibre loading varied from 0 to $3.0 w \%$ and tested in compression and flexure for cured strength after 7 and 28 days. The densities of the composites were also determined. The test results are compared for cement stabilized soil without fibre additions as well as between reinforcement with stalk or spikelet fibre. The introduction of fibres prominently improves the compressive and bending strength of the composites, suggesting possibilities of reducing cement additions by introducing natural fibre reinforcements. The improvement for spikelet fibre reinforced soil is consistently higher for spikelet fibres than for stalk fibre. The separation and differentiated use of stalk and spikelet presents the possibility of enhancing the sustainability of recycling EFB for competing uses in nutrient recycling and natural fibre production.
\end{abstract}

Keywords--- sustainability; natural fibres; cement-stabilised soil composites,; EFB, stalk; spikelet; compressive strength; flexural strength

\section{INTRODUCTION}

The construction and automobile sectors represent the highest consumers of raw and processed materials and any improvements in resource utilisation in these sectors is expected to have a big impact on sustainability of manufacturing and infrastructure development. Increasing socio-economic and environmental sustainability are providing construction industry being a global emerging sector in a highly developed and developing countries [1,2]. These two sectors are increasingly using composites in place of conventional materials and natural fibres are more actively investigated as reinforcements for both organic and inorganic matrix composites. The competitive advantage of natural fibres compared to synthetic polymeric, glass and carbon fibres is due to several factors including; environmental impact of production, renewable sources, industrial safety in producing and handling, higher specific strengths and lower production costs. .Earth is the oldest material used for buildings and the Egytians first used straw to stabilise earth more than 3000 years ago. About $50 \%$ of the world population use natural materials for their structures, with majority in Africa, Asia and Latin America. Sustained interest in earth buildings is attributed to availability of raw materials, low processing requirements, low cost, and low embodied energy [3]. The use of binders to improve the properties of earth is widespread and these include synthetic and natural fibres, lime and hydraulic cement. In the home construction sub-sector, earth-based composites are used in a variety of products such as walls, decking, fencing, window frames, panels and roofing/ceiling tiles.

Additives like cement and lime, bitumen and fibres have been used to ameliorate mechanical performance and longivity of soil blocks. Gaining the strengthing mechanisms differ according to additive. In the case of cement, this is typically achieved through additions of up to $15 \mathrm{wt} \%$ hydraulic cements $[4,5,6]$. Strength is also dependent on density and this can be controlled by the compaction pressure, for any given formulation. The introduction of cements however leads to issues of shrinkage that must be controlled and increases the embodied energy, thus reducing the sustainability of earth as a construction material. Fibres in stabilized earth brick decreses shrinkage and increases tensile and shearing strengths[7, 8, 9]. Consoli et al. (2002) [10] have reviewed that fibre-reinforced in cement treated soil increases the peak and residual shear strength with changes in their brittle to ductile behaviour. Both natural and synthetic fibres have been used and these studies have demonstrated that sisal [8], coconut fiber [11, 12], straw [13] and polyethylene [14] can all be feasible options. Agricultural residues as source of natural fibres are of particular interest because they can be available in 
large quantities from the cultivation and transformation of food and energy crops, as well as in significant quantities in rural settings

Palm oil is the most important seed oil globally and its production generates important amounts of fibrous waste, notably in the empty fruit bunch (EFB). Studies have shown that fibres from the empty fruit bunch can be used as reinforcement in polymers and cements, with improvements in performance EFB has also been investigated for many competing uses such as; nutrient recycling, renewable energy production, mulching and soil enhancer, substrate for mushroom and pulping for paper. All recycling options that do not return EFB to the farms will negatively affect farm-gate nutrient balance which compares the nutrients exported in marketable products with fertilizer inputs, resulting to reduced sustainability in farm practice (RSPO) Previous studies have demonstrated that fibres from the spikelet and stalk have different composition and properties [15]. A judicious exploitation of this residue for co-product development is expected to promote nutrient recycling as stipulated by the RSPO and improve the availability of eco-friendly materials for home constructions..

\section{MATERIALS AND METHODS}

Empty fruit bunches for stalk and spikelet were obtained from an oil mill of a national agro - industrial operator, Cameroon Development Corporation (C.D.C) located at Mondoni in the South West Region of Cameroon. The stalks and spikelet were shredded, the fibres obtained washed and then ground to pass through a $2 \mathrm{~mm}$ mesh sieve. Soil samples were obtained from Bamenda, North West Region of Cameroon from a sampling site $632820.96 \mathrm{~m} \mathrm{E} \mathrm{and} 662930.41 \mathrm{~m} \mathrm{~N}$ Soil sample was taken from the homogenous layers and below $150 \mathrm{~cm}$ from the top of soil to exclude all organic matter. Portland cement was a commercial grade used for home constructions produced by the national cement company CIMENCAM. The dry soil and cement were thoroughly mixed up manually with water consistently then fiber was introduced into the process. This process continued until the required results were obtained as tabulated below.

Table 1: Formulation of composites

\begin{tabular}{|c|c|c|c|c|c|c|c|c|}
\hline & \multicolumn{7}{|c|}{$\%$ Fibre } \\
\hline & & 0 & 0.25 & 0.50 & 0.75 & 2 & 2.5 & 3 \\
\hline \multirow{4}{*}{$\stackrel{\Xi}{0}_{\mathbb{D}^{\infty}}^{\mathbb{E}}=$} & 0 & - & - & - & - & - & - & - \\
\hline & 5 & - & - & - & - & - & - & - \\
\hline & 10 & - & - & - & - & - & - & - \\
\hline & 15 & - & - & - & - & - & - & - \\
\hline
\end{tabular}

Specimens of standard dimensions $(40 \mathrm{~mm} \times 40 \mathrm{~mm} \times 40 \mathrm{~mm})$ were cast for compressive strength determinations and prismatic specimens of $(40 \mathrm{~mm} \times 40 \mathrm{~mm} \times 160 \mathrm{~mm})$ were cast for bending strength. The moulds were filled and a pressure of $0,028 \mathrm{MPa}$ was applied on each of the sample in the mould. All the specimens were cured for a period of 7 and 28 days before test. Each mixture had ten samples and the total bricks manufactured were 560 samples each for fibre from stalk and spikelet.

\section{Production of stabilized earth samples}

The soil was first mixed with the cement to attain the homogenous structure before adding the fibres in the mixture. The low pressures applied compared to the typical pressures for producing CESB puts the samples closer to adobe, where no pressure is applied.

\section{Curing}

After demoulding, the specimens were cured inside a thick plastic pouch for required duration ( 7 and 28 days) before testing. The cement based composite was kept under thick plastic pouch paper to conserve moisture for hydration, 


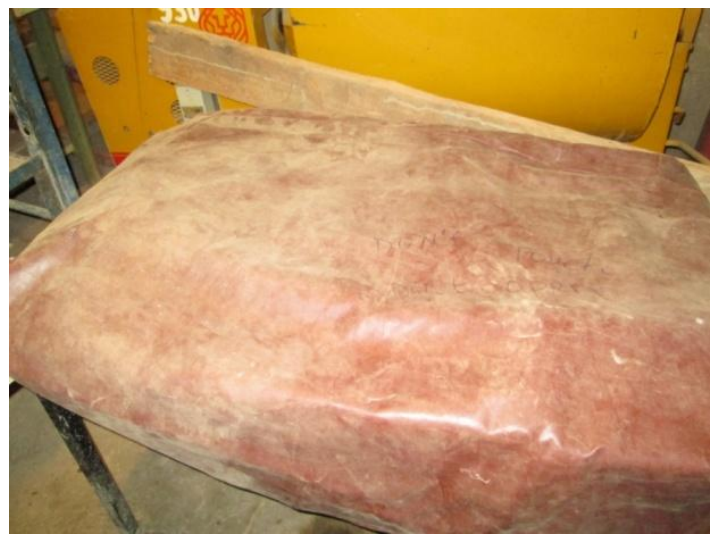

Figure 1: Sample in curing pouch

\section{Compression test}

The compressive test was carried out using RMU machine, serial 121288 in the civil engineering laboratory at the Government Technical High School BAMENDA

The hydraulic machine press was consistently applied on the specimen till failure occure to obtaine the maximum load.

The compressive strength was calculated from the maximum load recorded before failure, by.

Compressive strength $=F C / A$

Where:

Fc: force measured from the compression test machine in $\mathrm{N}$

A: area of the composite brick in $\mathrm{mm}^{2}$

\section{Flexural test}

The three point bending test were carried outusing RMU machine serial 1461288. The loading arrangement as shown in Figure 3

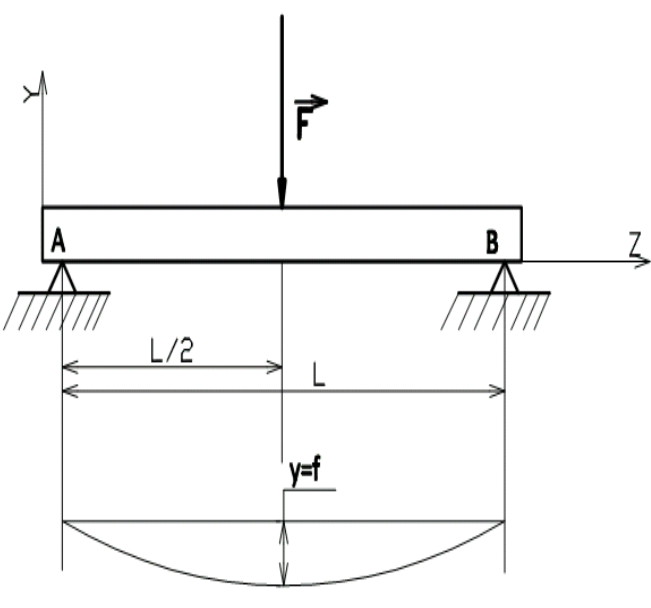

Figure. 2a: 3 point bending test
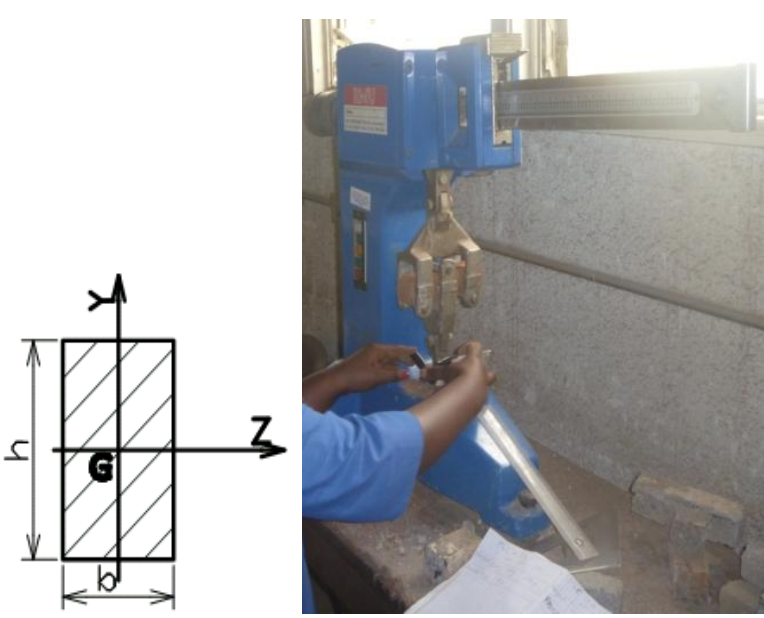

Figure. 2b: Flexural Machine

\section{The moisture contents of the EFB fibre.}

Moisture content was carried out using gravimetric method in a muffle furnace. $10 \mathrm{~g}$ of fibre sample was weighed and dried at $104^{\circ} \mathrm{C}$ in an oven for $24 \mathrm{hrs}$. The sample were weighed immediately on removal from the oven and stored. The calculations were done as follows:

$$
\% \text { of moisture content }=\frac{\text { (weight of wet sample }- \text { weight of dry sample ) X } 100}{\text { weight of dry sample }}
$$


The water absorption contents of the EFB fibre.

The determinations of water absorption (WA) were performed. These were carried out by immersing EFB Fibres in distilled water, at room temperature. After every 2 hours, the samples were removed and the surfaces were dried up using a dry towel for reweighing with a balance of $0.001 \mathrm{mg}$ precision within a minute. The water absorption of each specimen calculations were done as follows:

$$
\text { Water absorption } \%=\frac{\text { (weight of wet sample }- \text { weight of dry sample ) X } 100}{\text { weight of dry sample }}
$$

\section{RESULT AND DISCUSSION}

\section{DENSITY}

Figure 3 reveals that the density of stalk and spikelet reduces with an increase in fibre content

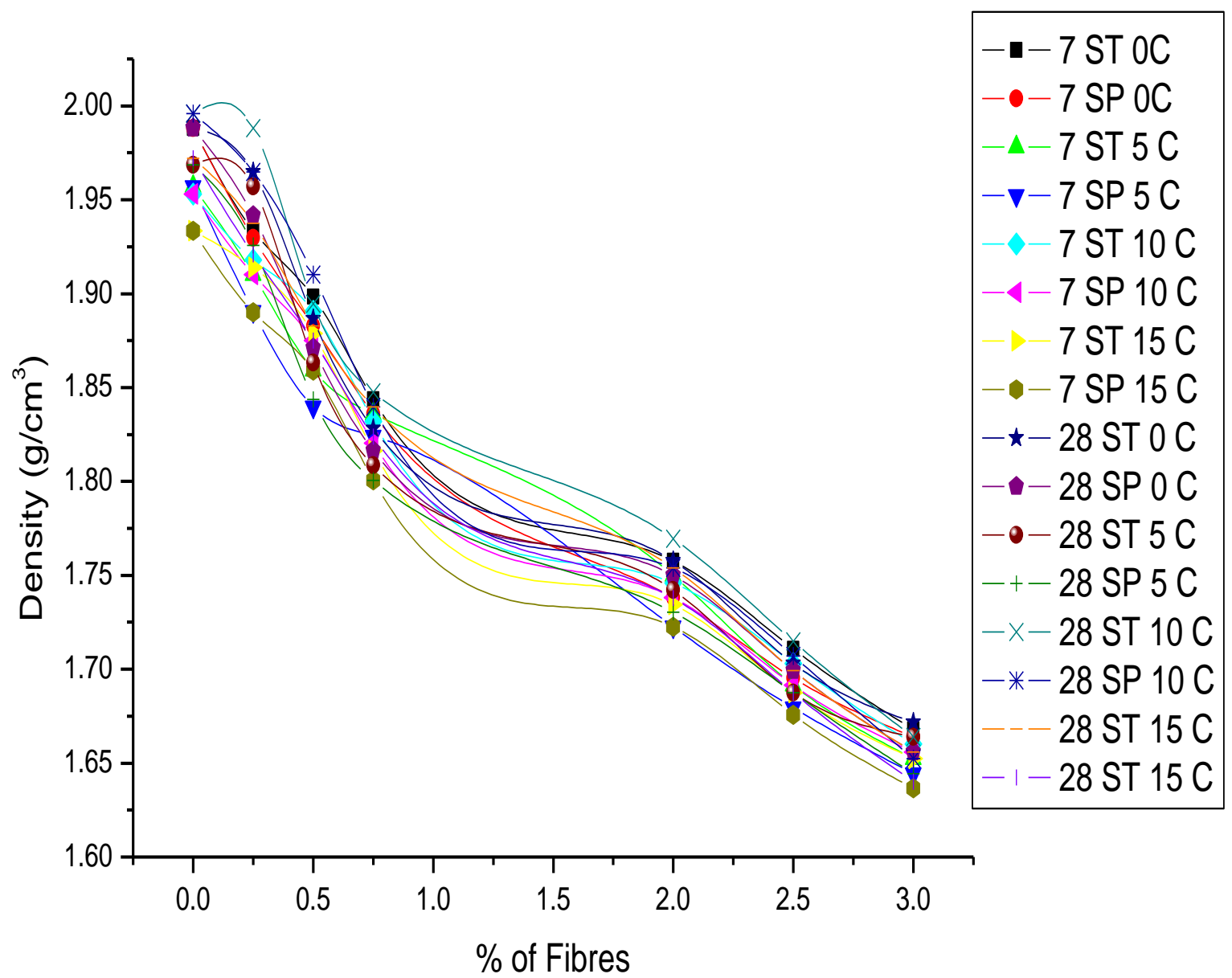

Figure 3: Densities of stabilized reinforced composites

This trend is evident in the plot of the percentage of fibres against the densities of the sample as shown in figure 3 . The densities of composites with relatively high fibre loadings ( 2 to $3 \%$ ) lie just above the upper limit of the density of lightweight concrete blocks. 
Other researchers $[16,17]$ have reported the decrease in density of cement-stabilized blocks with increase in fibre content and highlighted the potential usefulness for thermal isolation of buildings, especially in regions with extreme climate changes.

$$
\text { Compression strength }(\mathrm{MPa})=\mathrm{Fc} / \mathrm{A}
$$

\section{Calculation of compressive strength and statistical analysis}

The previous data was analyzed with $99 \%$ confidence bounds in the software Matlab version 7.7

The average compressive strength of the samples on fibre from stalk and spikelet composites after 7 days is presented in figure 4 below. It was observed that the results show a little improvement in the compressive strength with an increase of fibre for 7 days of curing.

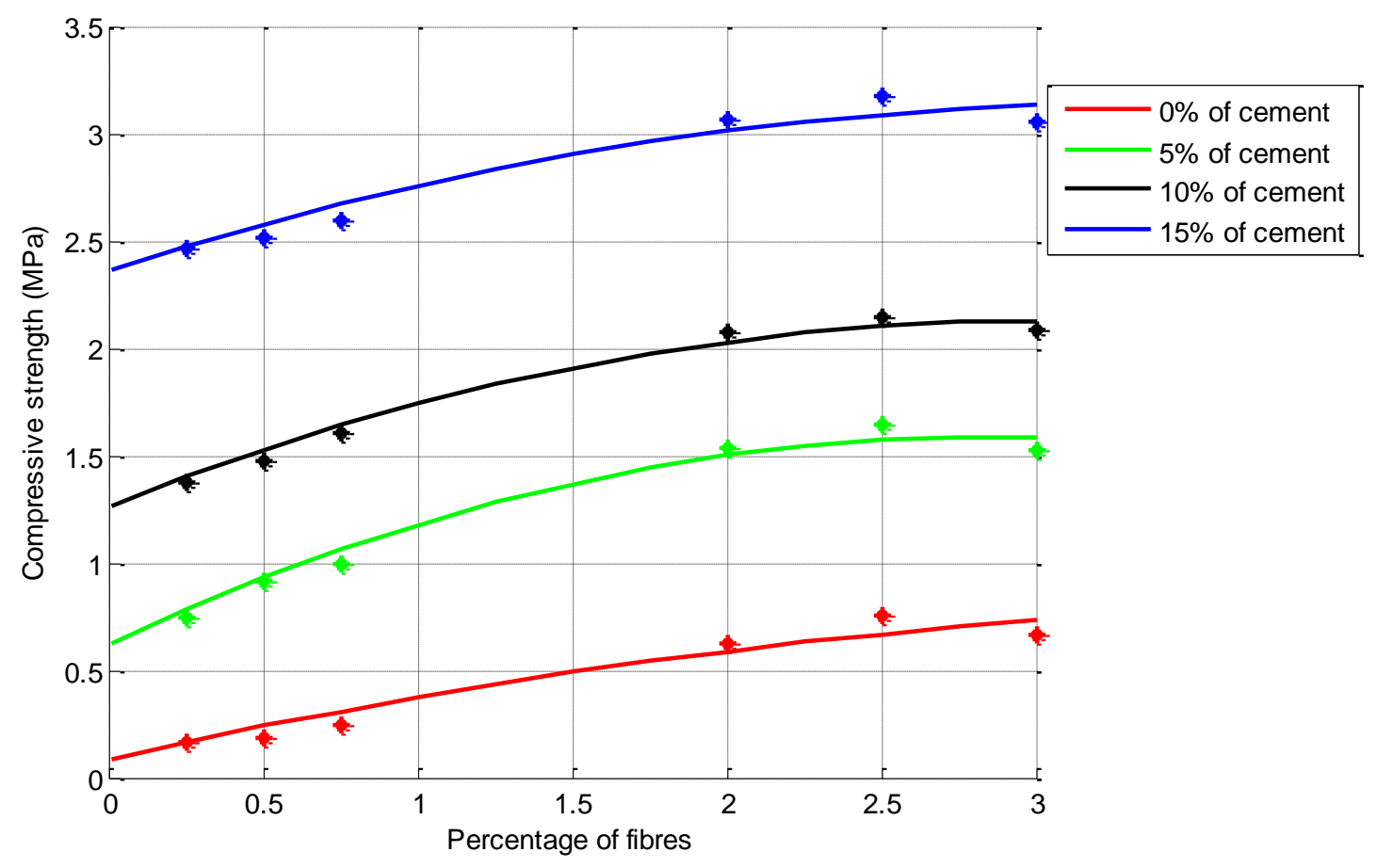

Figure 4: Average Compressive strength vs \% Stalk fibres for 7 days of curing 


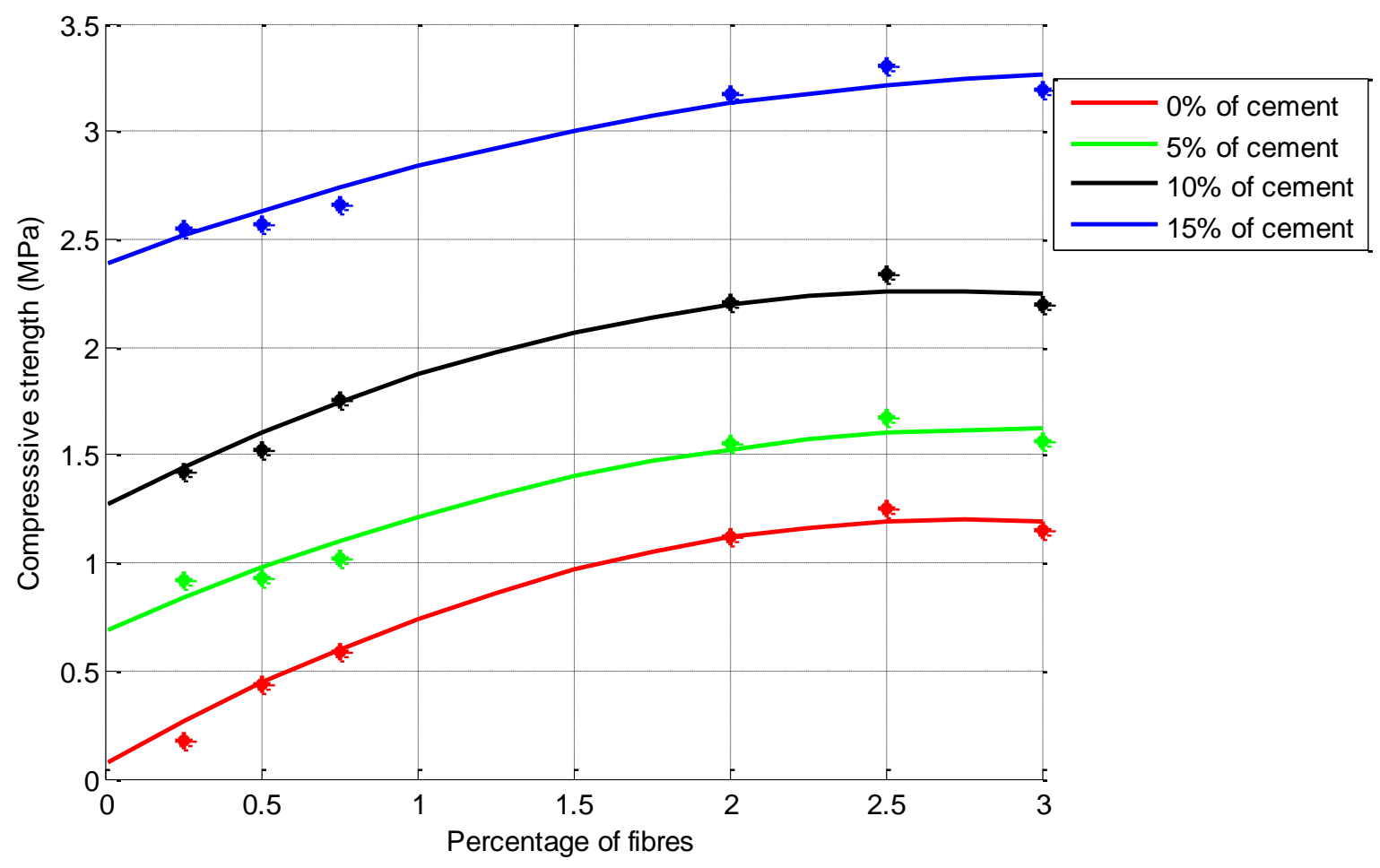

Figure 5: Average Compressive strength vs \% spikelet fibres for 7 days of curing

Table 2: Equations for prediction of Average Compressive strength of stalk and Spikelet composites for 7 days of curing

\begin{tabular}{lcc}
\hline $\begin{array}{c}\text { \% } \\
\text { cement }\end{array}$ & $\begin{array}{c}\text { Average Compressive strength } \\
\text { Stalk (MPa) }\end{array}$ & $\begin{array}{c}\text { Average Compressive strength } \\
\text { Spikelet (MPa) }\end{array}$ \\
\hline $\mathbf{0}$ & $\sigma_{s t}=-0.03666 w_{f}^{2}+0.3244 w_{f}+0.08732$ & $\sigma_{s p}=-0.1481 w_{f}^{2}+0.8195 w_{f}+0.07114$ \\
$\mathbf{5}$ & $\sigma_{s t}=-0.1169 w_{f}^{2}+0.6717 w_{f}+0.6247$ & $\sigma_{s p}=-0.1085 w_{f}{ }^{2}+0.6375 w_{f}+0.6864$ \\
& & \\
$\mathbf{1 0}$ & $\sigma_{s t}=-0.09366 w_{f}{ }^{2}+0.5677 w_{f}+1.268$ & $\sigma_{s p}=-0.1372 w_{f}{ }^{2}+0.7367 w_{f}+1.272$ \\
$\mathbf{1 5}$ & $\sigma_{s t}=-0.06815 w_{f}{ }^{2}+0.4608 w_{f}+2.363$ & $\sigma_{s p}=-0.07814 w_{f}{ }^{2}+0.5264 w_{f}+2.389$ \\
\hline
\end{tabular}




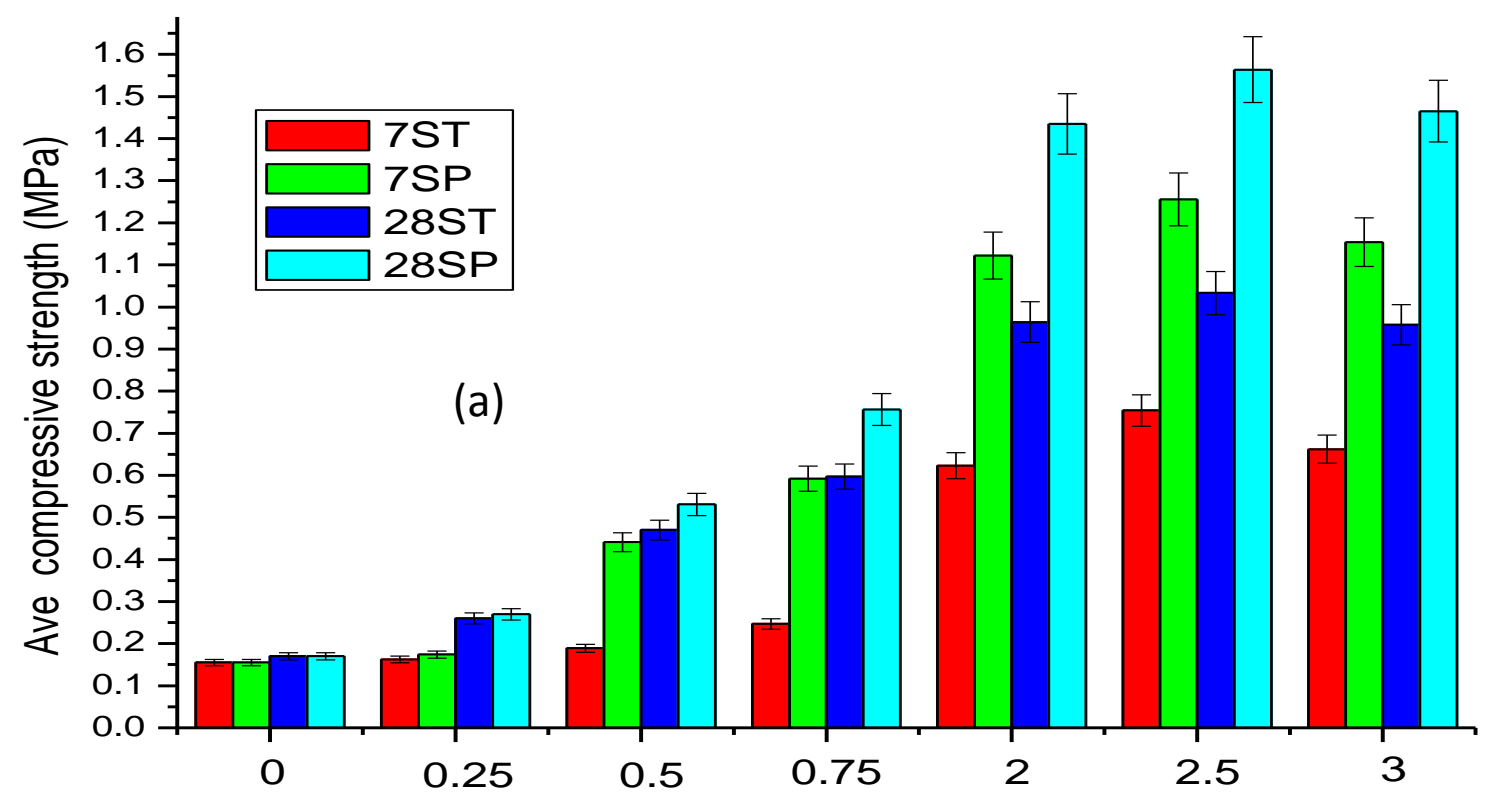

Fibre \%

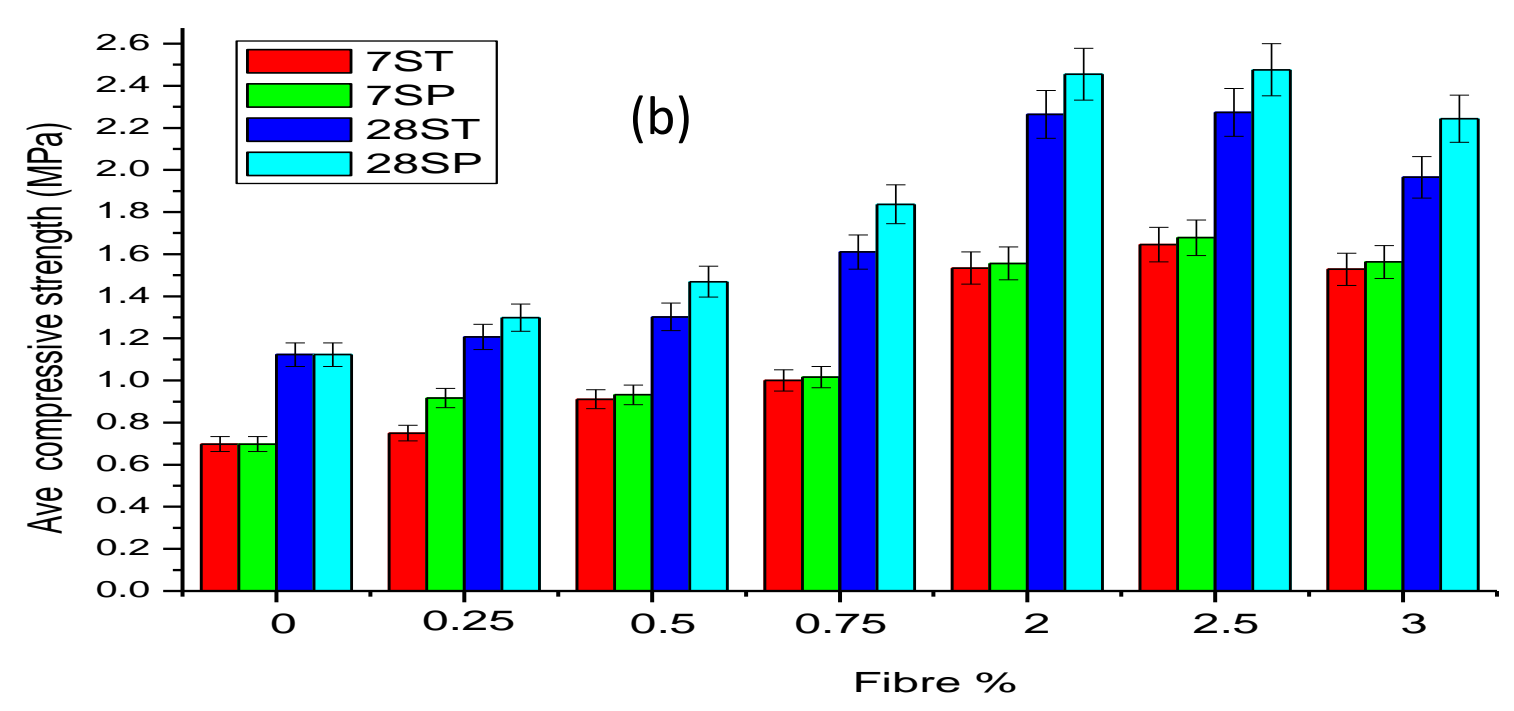



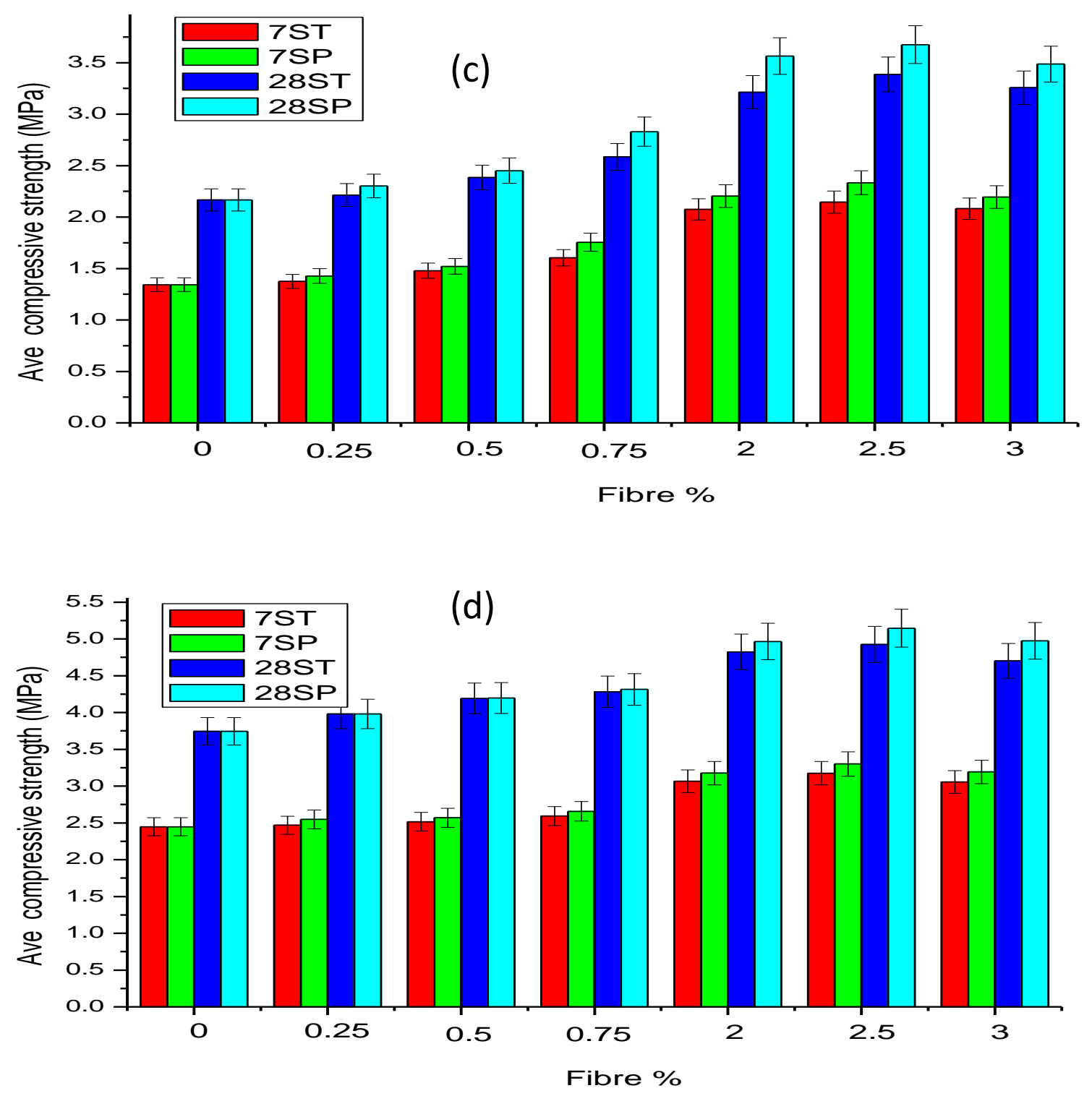

Figure6: Compressive error bar for 7 and 28 days with a) $0 \%$ cement b) $5 \%$ cement c) $10 \%$ cement d) $15 \%$ cement

The introduction of fibres improves compressive strength for all formulations, with the highest improvements (up to $400 \%$ ), recorded for mixtures without or low cement additions (up to 200\%). The compressive strengths lie well within the range of $1-4 \mathrm{MN} / \mathrm{m} 2$ recommended for single storey buildings for most of the formulations. The exceptions are formulations with $0 \%$ cement and fibre loadings lower than $2 \%$, and $5 \%$ cement at fibre loadings lower than $0.5 \%$. At high fibre loadings the performance of the composites containing 5\% cement and above approaches or exceeds the $2.8 \mathrm{MN} / \mathrm{m}^{2}$ recommended for precast masonary units and load bearing fired clay bricks.

\section{Flexural Test Results on stalk and spikelet Composites}

Flexural strength $\sigma=\frac{3 \mathrm{FL}}{2 \mathrm{bh}^{2}}$ for a rectangular cross section

For 560 samples tested, failure mostly occurred at the mid point Typical Young Modulus vs \% of fibres are presented in modeling of flexural results. In this study the Young Modulus and tensile strength were higher in the spikelet than the stalk. Generally, the fibre-reinforced soil performed better inpost-initial crack behaviour compared to the plain matrix. The non-reinforced samples exhibited sudden failure in all instances whilst more graudual was observed for all fibre-reinforced samples 
. Figure 7 represent the variation strength of stalk and spikelet The flexural test increases significantly with increase in fibres content but drops at fibre content beyond $3 \mathrm{wt} \%$. probably due to various factors such as fibre to fibre interaction, voids and dispersion problems. In all cases stalk composites show inferior performance to spikelet composites either with or without cement. The differences are most pronounced at low cement content.

The variation of specific strength of both the stalk and spikelet composites with different cement content is presented The improvement in strength for the composites with the addition of fibres content is more significant at lower cement additions.

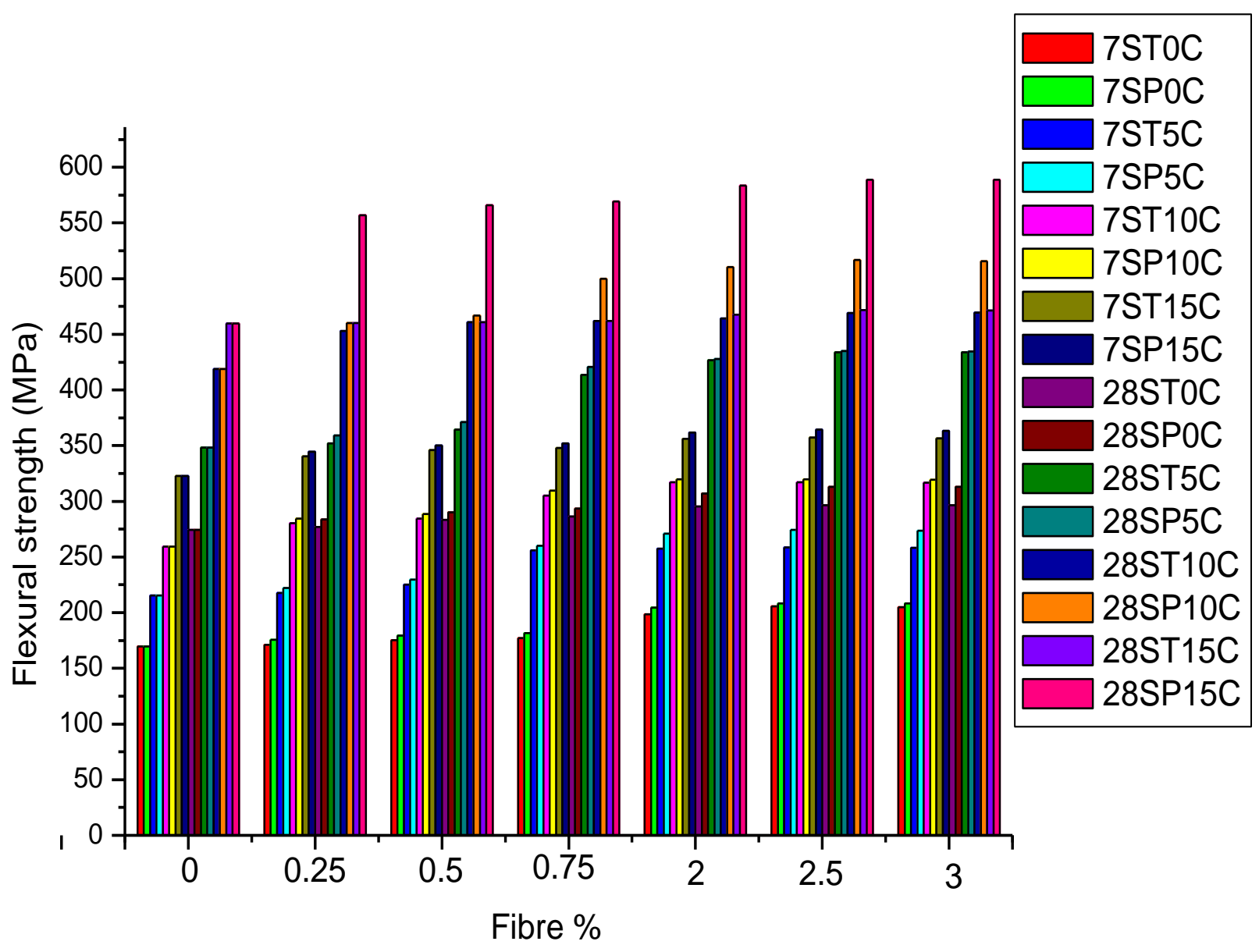

Figure 7: The Flexural Strength of composite

\section{Shear Strength}

. The differents Shear Strength of stalk and spikelet is presented in Figure 8. The shear strength shows some slight increase with addition of fibres content up to $2.5 \%$ where further addition of fibres content decreases. This trend is exhibited by both stalk and spikelet cement-stabilised soil composites. This reduction may be due to the formation of voids in the matrix which is generally located at the inter-laminar region of composites. In the present investigation, the maximum value of shear strength has been recorded for the spikelet composite with $2.5 \%$ of fibres. 


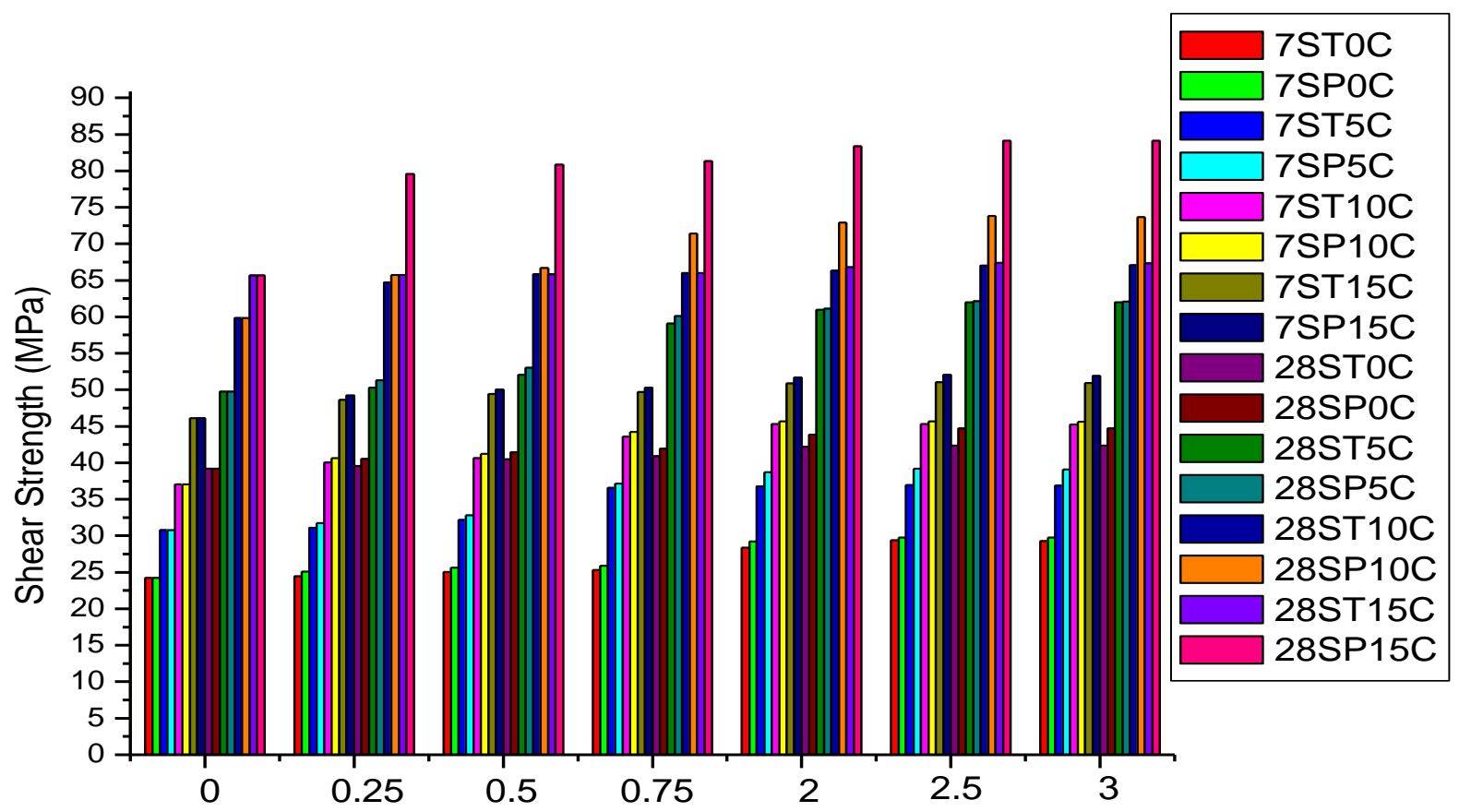

Fibre \%

Figure 8: The Shear Strength of composites

Fibres are known to oppose crack formation in step with increasing stress and also bridge micro cracks from expanding [18].

It was also observed that some of the fibres bridged cracks. In this study, the fibres from the spikelet had a higher Young Modulus and produced a higher strength in matrices compared to the stalk fibres.

\section{Moisture content}

The moisture content of EFB fibres was higher in stalk than spikelet and review from the other researcher that the results was within the range as summarized in table 3 below

Table 3: Moisture content

\begin{tabular}{lll}
\hline Fibres & Moisture Content & Author \\
\hline EFB & $2.2-9.5 \%$ & Mohd et al (2009) \\
EFB & $10.4 \%$ & Ismail et al (1997) \\
STALK FROM EFB & $7.31-10.28 \%$ & Present study \\
SPIKELET FROM EFB & $2.18-6.42 \%$ & Present study \\
\hline
\end{tabular}

The higher the moisture content of the natural fibre the higher is the change in the mechanical and physical properties of composite can be affected and it leads to poor wettability with matrix which results in a weak interfacial bonding between the fibre and matrix [19].

\section{Water absorption}

The water absorption rate is higher in stalk than in spikelet. This may be due to the bigger viol found at the middle of the stalk of EFB fibres. The maximum water absorption of stalk and spikelet were $158.48 \%$ and $177.97 \%$ respectively. The water absorption of different part of EFB oil palm is presented in figure 9 below. 


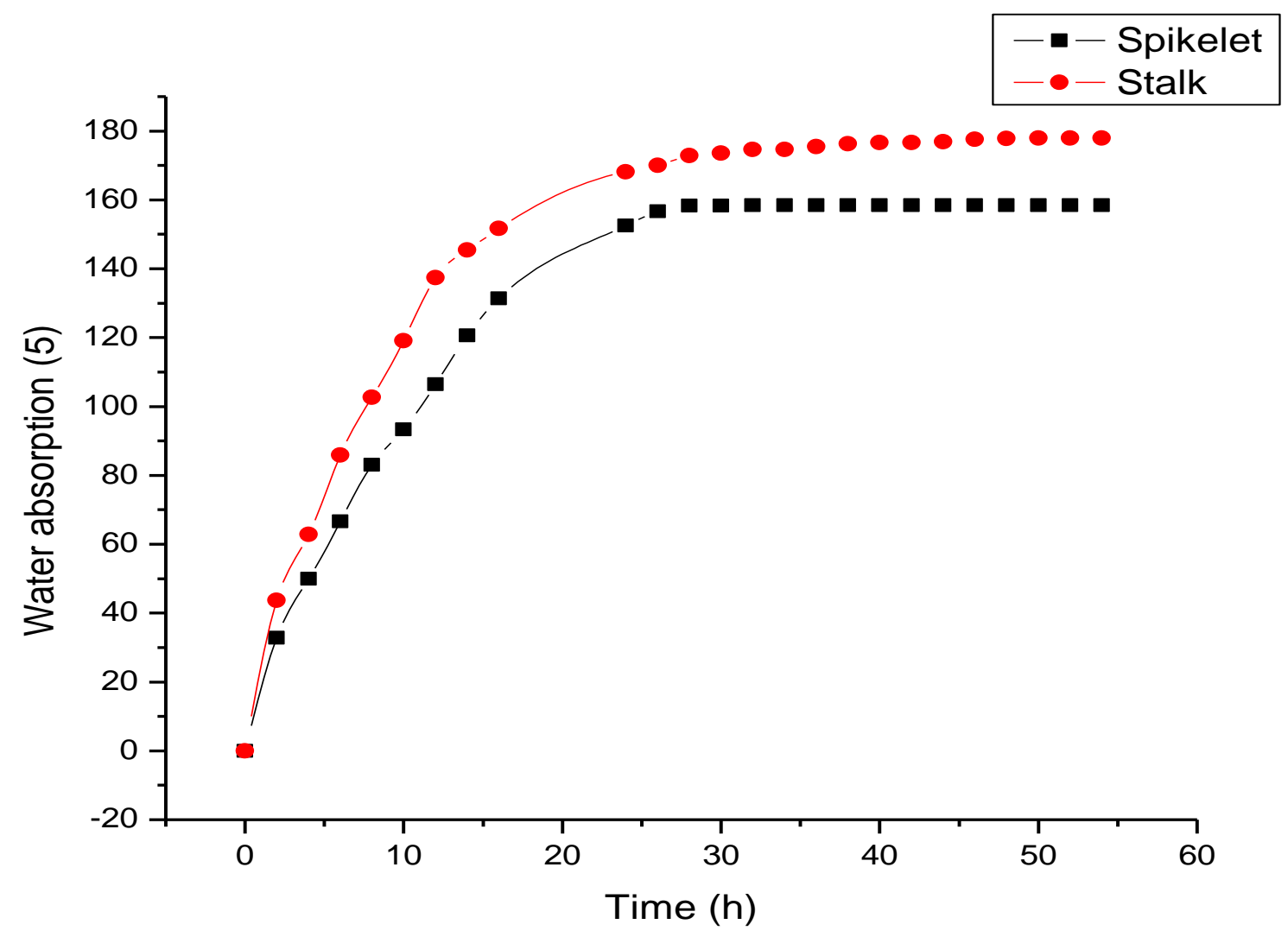

Figure 9: Water absorption of Stalk

The water absorption by the fibre is due to the fact that areca fibre contains very high percentage of hemicellulose in its structure. Also, in all natural cellulose fibres, a hollow cavity called lumen exists in the unit cell of the fibres which generates more pathways for water to diffusing into the fibre [20]. It also shows that the percentage of water uptake decreased with an immersion time. This is attributed to the fact that the initial and second absorption phases are governed respectively by the wetting of fibres and the capillary absorption process where the water diffuses into the fibres until reaching a maximum absorption. When the immersion time becomes significant, a decrease in the water absorption is due to the hydrophilic property of cellulosic fibres as more water molecules penetrate into the micro cracks present in these fibres, making the fibres swell and eventually leading to failure [21, 22] . It shows that alkali treatment had improved the ability of EFB fibres to absorb water. This improvement is likely due to the removal of the oil and waxy substances from the raw fibres. It is stated that an alkali treatment results in the partial dissolution of hemicellulose [23]. Hemicellulose, however, is responsible for the water absorption of the fibre [24]. The alkali treatment leads to a partial removal of waxes and therefore an increased accessibility of the protanable surface functions. An increased number of 'polar' surface functionalities will increased the amount of water absorbed on the fibres $[25,26]$. The swelling process was much faster leading to higher water uptake and also removed the protecting cell-fibres, thus increasing the water absorption. This improvement could also be explained by both the change in the quality of the surface of the areca fibres after alkali treatment and the presence of several hydroxyl groups on these surfaces [27].

\section{CONCLUSION}

Our study aims at the influence of stalk and spikelet fibre on the mechanical properties of stabilized soil as a strategy for improving the sustainability of recycling EFB and use of cement-stabilised soil in buildings. The results show that there are significant improvements in mechanical performance with the introduction of fibres and differences in the influence of the fibres from the different parts of EFB on mechanical and physical properties. Fibres from the spikelet have superior performance to fibres from the stalk as reinforcement for cement-stabilised soil.

The increase in flexural and compressive strength values peaked at fibre loading of $2.5 \%$ fibre content by weight. with the maximum value of strength for our samples were recorded at $2.5 \%$ of fibres. The incorporation of fibres into the matrices prevented sudden failure of the tested samples during the test. 


\section{ACKNOWLEDGMENTS}

We would like to thank the Government Technical High School Bamenda, Cameroon where the experimental works were performed.

\section{REFERENCES}

[1] Industry and environment, (2006) Sustainable building and construction initiative: information note. <http://www.uneptie.org/pc/pc/SBCI/SBCI_InformationNote.pdf>; [15.09.06].vol.26.N2-3.

[2] Agenda 21 for Sustainable Construction in developing countries: a discussion document. CSIR Building and Construction Technology; 2004.ISBN0798855401.

[3] Walker, P.J. (2004) Strength and erosion characteristics of earth blocks and earth block masonry. J. Mater. Civ. Eng, $16,497-506$.

[4] Rigassi, V. (1995). Compressed earth blocks. Manual of production. Vieweg, Eschborn, Germany.volume 1

[5] Namango, S., (2006), "Development of cost-effective earthen building material for housing wall construction: investigations into the properties of compressed earth blocks stabilized with sisal vegetable fibers, cassava powder and cement compositions", PhD Thesis, Brandenburg University of Technology, Germany.

[6] Morton, T., (2008), "Earth masonry: Design and construction guidelines”, BRE Press, Bracknell, Berkshire, UK.

[7] Khedari J., Watsanasathaporn P., and Hirunlabh J., (2005), "Development of fibre-based soil-cement block with low thermal conductivity", Cement \& Concrete Composites, 27:111-116.

[8] Obonyo, E. (2011), "Optimizing the physical, mechanical and hygrothermal performance of compressed earth bricks", Journal of Sustainability, 3(4):596-604.

[9] Binici,H., Aksogan, O., and Shah, T., (2005), "Investigation of reinforced mud brick as building material," Construction and Building Materials, 19(4):313-318.

[10] Elenga R.G., Mabiala B., Ahouet L., and Goma-Maniongui J. and Diris G.F. (2011), "Characterization of clayey soils from Congo and physical properties of their compressed earth blocks reinforced with post-consumer plastic wastes", Geomaterials, 1:88-94.

[11]Consoli, N. C., Montardo, J. P., Prietto, P. D. M., and Pasa, G. S. (2002)."Engineering behavior of a sand reinforced with plastic waste."J. Geotech. Geoenviron. Eng., 128 (6), 462-472.

[12] Mesbah A., Morel, J. C., Walker, P. and Ghavami, K., (2004), "Development of a direct tensile test for compacted earth blocks reinforced with natural fibers", Journal of Materials in Civil Engineering, 16:95-98.

[13] Minke G., (2009), "Building with Earth: Design and Technology of a Sustainable Architecture", Birkhäuser Publishers for Architecture

[14] Kestner, D., Goupil, J., and Lorenz, E. eds. (2010), "Sustainability Guidelines for the Structural Engineer", American Society of Civil Engineers.

[15] Yakum R. N., Josepha F. T., Ebenezer N., Gossett O., Kavian O. C., (2015);Extraction and Characterization of fibres from the Stalk and Spikelet of Empty Fruit Bunch (EFB);HindawiPubishing Corporation; Journal of Applied Chemistry; volume 2015; article ID 750818; 3 pp 1-10

[16] Turgut, P. and Yesilata, B., (2008). Physicomechanical and thermal performances of newly developed rubber-added bricks, Energy and Buildings, 40, (5): 679- 688.

[17] Binici, H., Aksogan, O., Nuri, B. M., Akca, E., \&Kapur, S. (2007). Thermal isolation and mechanical properties of fibre reinforced mud bricks as wall materials. Construction and Buildings Materials, 21, 901-906.

[18] Marwan Mostafa. andNasim Uddin.; (2015), Effect of Banana Fibers on the Compressive and Flexural Strength of Compressed Earth Blocks. Journal of Buildings 5, 282-296; doi:10.3390

[19] Biswas, S and A. Satapathy, 2010. A comparative study on erosion characteristics of red mud filled bamboo-epoxy and glass-epoxy composites. Materials and Design, 31: 1752- 1767. 
[20] Reddy N. and Yang Y., (2005). Biofibres from Agricultural By products for Industrial Applications. Trends in Biotechnology, 23 (1):22-27.

[21] Nosbi,N.,H.M .Akil,Z.A.M. IshakandA. Abubaker, (2011). Behavior of Kenaf Fibres after Immersion in Several Water Conditions, BioResources, 6(2):950-960.

[22] Saikia, D.(2010). Studies of Water Absorption Behaviourof Plant Fibresat Different Temperatures. International Journal of Thermophysics, 31(4-5),1020-1026.

[23] Rong, M. Z., Zhang M. Q., Liu Y., Yangand G.C., Zeng H. M., (2001). The Effect of Fibre Treatment on the Mechanical Properties of Unidirectional Sisal-Reinforced Epoxy Composites. Composite Science and Technology, 61(10):1437-1447.

[24] Nabi,D and Jog J.P., (1999). Natural Fibre Polymer Composites: Areview. Advances in Polymer Technology, 18 (4): 351-363

[25] Prasad, S.V., C. Pavithranand P.K. Rohtgi, (1983). Alkali Treatment of Coir Fibresfor Coir-Polyester Composites. Journal of Material Science,18(5),1443-1454.

[26] Bismarck A., Mohanty A. K., Askargorta I. A., Czapla S., Misra M, Hinrichsen G. and Springer J., (2001). Surface Characterization of Natural Fibres; Surface Properties and the Water Up-Take Behaviour of Modified Sisal and Coir Fibres. Green Chemistry, 3(2):100-107.

[27] Bal, K. E., Bal Y. and Lallam A., 2004. Gross Morphology and Absorption Capacity of Cell-Fibres from the Fibrous Vascular System of Loofah (Luffacylindrica). Textile Research Journal, 74(3):241-247. 